\title{
Obstruction-induced alterations within the urinary bladder and their role in the pathophysiology of lower urinary tract symptomatology
}

\author{
Christos Komninos, MD, MSc, FEBU,; Iraklis Mitsogiannis, MD, PhD, FEBU ${ }^{\dagger}$ \\ "Department of Urology, Nikaia General Hospital, Athens, Greece; ' $2^{\text {nd }}$ Department of Urology, University of Athens Medical School, Athens, Greece
}

Cite as: Can Urol Assoc J 2014;8(7-8):e524-30. http://dx.doi.org/10.5489/cuaj.1636 Published online August 11, 2014.

\section{Abstract}

Benign prostatic hyperplasia $(\mathrm{BPH})$ is considered a frequent cause of bladder outlet obstruction (BOO) and lower urinary tract symptoms. This review addresses the bladder response to $\mathrm{BOO}$ and focuses on the alterations and biochemical adaptability of the bladder wall in the presence of hypoxia. A literature review of published articles has been performed, including both in vivo and in vitro studies on human and animal tissue.

\section{Introduction}

Benign prostatic hyperplasia (BPH) accompanied by bladder outlet obstruction (BOO) affects $30 \%$ of men over $60 . .^{1}$ It is a common disorder of the male urogenital tract and clinically presents with lower urinary tract symptoms (LUTS), such as hesitancy, straining, weak urine flow, frequency, nocturia and urgency. ${ }^{2} \mathrm{BPH}$-related symptomatology is attributed to obstructed outflow (BOO), which results from either prostate enlargement (static component) and/or increased $\alpha$-adrenergic activity at the level of bladder neck and prostatic urethra (dynamic component). ${ }^{3,4}$

BOO can also be associated with a variety of morphological, contractile and biochemical changes within the bladder in both experimental and clinical studies. The symptomatic presentation of the disease is related largely to these degenerative changes that occur in the bladder. In general, the bladder modifies its structure to compensate the increased resistance to flow, while significant hypoxia ensues because of the high resistance to flow and consequent high intravesical pressure.

The present review addresses current data on the response of the bladder to BOO, particularly focusing on the bladder wall alterations and biochemical adaptability in the presence of hypoxia.

\section{Methods}

For this study, we used in vivo and in vitro studies on human tissue and animal model experiments to estimate the consequences of outlet obstruction on the bladder wall. A search of the PubMed, Scopus and Web of Science databases using the terms "prostatic hyperplasia," "urinary bladder neck obstruction," "urinary bladder" and "prostate" was conducted. The research focused on articles describing the alterations within the bladder wall induced by $\mathrm{BOO}$.

The study population were human and animal models with BOO. Two authors independently screened the titles and abstracts of the articles identified from the search for relevance. Outcome parameters were the morphological and biochemical changes occurring within the bladder wall of subjects with outlet obstruction, associated with the development of LUTS. The research was limited to the period from 1980 to 2013. Only English peer-reviewed studies were included. If some articles were republished by the same authors, we included only their newest version in the reviewing process. The same process was followed in case of similar articles written by different groups.

We excluded manuscripts that were irrelevant to the objective of this review, as well as those published only in abstract form. Any disagreement was resolved by discussion and final decision was based on a consensus. In the end, 64 manuscripts were included (Fig. 1).

\section{Results}

\section{Structural changes in the bladder wall}

The urinary bladder often responds to $\mathrm{BOO}$ with hypertrophy, accompanied by an augmentation of connective tissue components and replacement of proteins of the contractile apparatus of the smooth muscle cell, with their non-muscle (embryonic) isoforms, such as non-muscle myosin heavy 


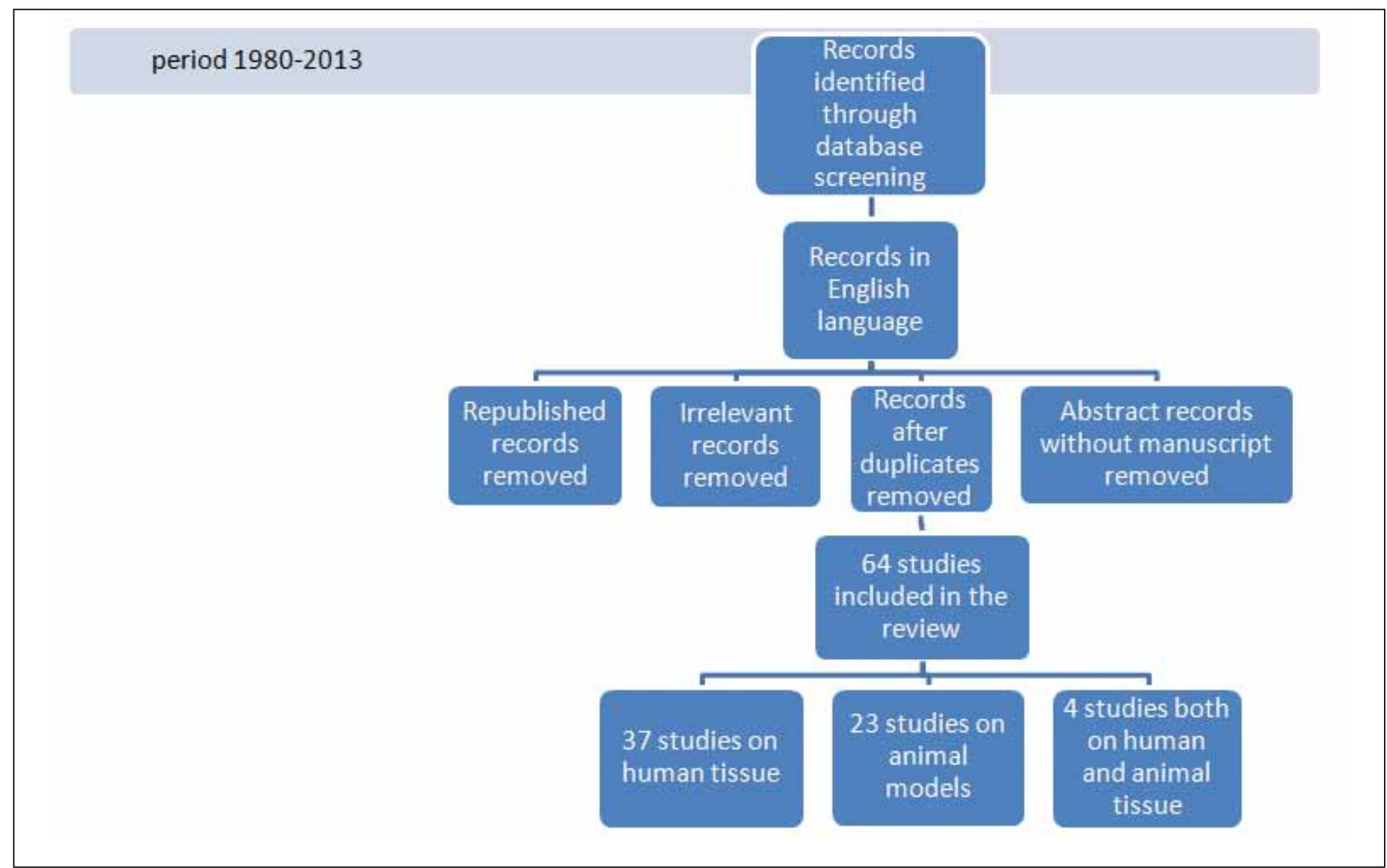

Fig 1. Flow diagram of the reviewing process.

chain (MHC), a-isoform of tropomyosyn, calponin, $\beta$ - and $\gamma$-actin. ${ }^{5-10}$ Detrusor muscle myosin is a type II myosin composed of two pairs of heavy (MHC) and light (MLC) chains. Two MHC isoforms have been identified in the detrusor muscle, namely isoform 1 (204 kDa) and isoform 2 (200 kDa). In an animal study, the relative amount of MHC isoform 2 decreased during obstruction-induced bladder wall hypertrophy; however, the overall concentration of myosin in the smooth muscle cells increased, whereas the concentration of actin was unchanged. These alterations were normalized after removal of the obstruction, suggesting that the turnover of contractile and cytoskeletal proteins is fast and can be regulated in response to changes in the increased functional demands in smooth muscle, due to the high urethral resistance during BOO. ${ }^{8}$

High bladder pressure induces adaptive changes in the bladder structure, which, in the long term, are visible as muscle enlargement and collagen deposition. ${ }^{11-13}$ The increase in connective tissue between muscle fibres and muscle bundles significantly decreases bladder elasticity and therefore bladder compliance..$^{14}$ In a recent study, Metcalfe and colleagues demonstrated that, in partially obstructed rat bladders, the progression to fibrosis is typically accompa- nied by increased levels of epidermal growth factor (EGF), insulin-like growth factor 1 (IGF-1) and connective tissue growth factor (CTGF). ${ }^{15}$

Obstruction-induced smooth muscle remodelling and hypertrophy are compensatory responses aimed to produce the increased force required to expel urine against the obstruction. These compensatory changes are associated with altered expression of contractile proteins and various signalling and regulatory proteins, such as calmodulin, Rho-activated kinase and caveolins. ${ }^{16-20}$ At the cellular level, muscarinic receptor-mediated bladder contraction involves two main pathways, voltage-operated $\mathrm{Ca}^{++}$channels and a Rho-kinase. While the opening of the sensitive $\mathrm{Ca}^{++}$channels allows for a marked elevation of intracellular $\mathrm{Ca}^{++}$concentrations resulting in contraction, the Rho-kinase constitutes a main pathway, which enhances detrusor $\mathrm{Ca}^{++}$ sensitization necessary for the detrusor muscle to maintain contraction. ${ }^{16}$ The expression of Rho-kinase is abnormally upregulated in the hypertrophied urinary bladder, resulting probably in alterations of muscle relaxation in the prostate, bladder neck and urethra in the voiding phase, as well as detrusor overactivity in the storage phase. ${ }^{20}$ Animal studies indicate that Rho-kinase inhibitors may have a role as future 
treatments for bladder dysfunction. ${ }^{17}$ Phosphodiesterase-5 inhibitors (PDE5-Is) induce down-regulation of Rho-kinase activity and this could probably explain their significant efficacy in patients with BOO. ${ }^{21}$

As a result of the structural changes of the bladder wall occurring during $\mathrm{BOO}$, the bladder function can remain relatively normal as the hypertrophying detrusor initially counteracts the progressive increase in urethral resistance. The limited changes in micturition pressure and flow characteristics that occur during the compensated function are not usually disabling enough to motivate patients to seek medical attention. During the progress of the disease, mainly due to the ischemia influence, bladder function will begin to deteriorate and finally the bladder will become decompensated.

\section{Adjustment to bladder wall ischemia}

$\mathrm{BOO}$ and the ensuing muscle hypertrophy and collagen deposition within the bladder wall result in a significant decrease in detrusor blood flow and hence impaired oxygen diffusion to the tissues. ${ }^{22}$ Focal hypoxia occurs early in the initial response, activating angiogenic regulators which induce the construction of new blood vessels within the interstitial spaces around the muscle bundles. ${ }^{22-27}$ The expression of angiostatic factors, such as Endostatin XV, due to the constantly increased collagen deposition and subsequent fibrosis, results in inhibition of further angio- genesis, decreasing blood flow, continuing ischemia injury and gradual progression to end-stage decompensation. ${ }^{28-30}$

During the compensation phase, an increased expression of hypoxia inducible factor-a (HIF-a) is observed (Fig. 2a). ${ }^{31}$ HIF-a stimulates angiogenesis at a rate that enables vascular density and blood flow to increase relative to the increase in bladder mass. ${ }^{22}$ Moreover, HIF-a also increases glucose uptake and availability for glycolysis and stimulates transcription of a wide range of gene products, some of which alter the metabolism of the cell to enable it to survive better in a hypoxic environment. ${ }^{32}$ In a study in rats, Ghafar and colleagues showed that $\mathrm{BOO}$ resulted in a significant increase in HIF-a, vascular endothelial growth factor (VEGF) and angiopoietin-1, suggesting that oxygen perfusion of the hypertrophied muscle bundle is affected. ${ }^{32}$ It has been proposed that during obstruction, the detrusor reduces its own oxygen supply by producing pressures that compress the small blood vessels. ${ }^{33,34}$ Prevention of bladder wall ischemia may potentially lead to a lesser degree of detrusor hypertrophy and hence bladder dysfunction; new treatment approaches towards this direction are currently being studied..$^{35}$

These findings were recently confirmed in humans by Mcnab and colleagues, by using new imaging technologies. ${ }^{36}$ The authors performed a study in which the changes in tissue oxygenation and hemodynamics of 14 asymptomatic and 6 subjects with LUTS, were monitored using near-infrared spectroscopy (NIRS). The results indicated an overall reduction in the detrusor blood volume and the availability of oxy-

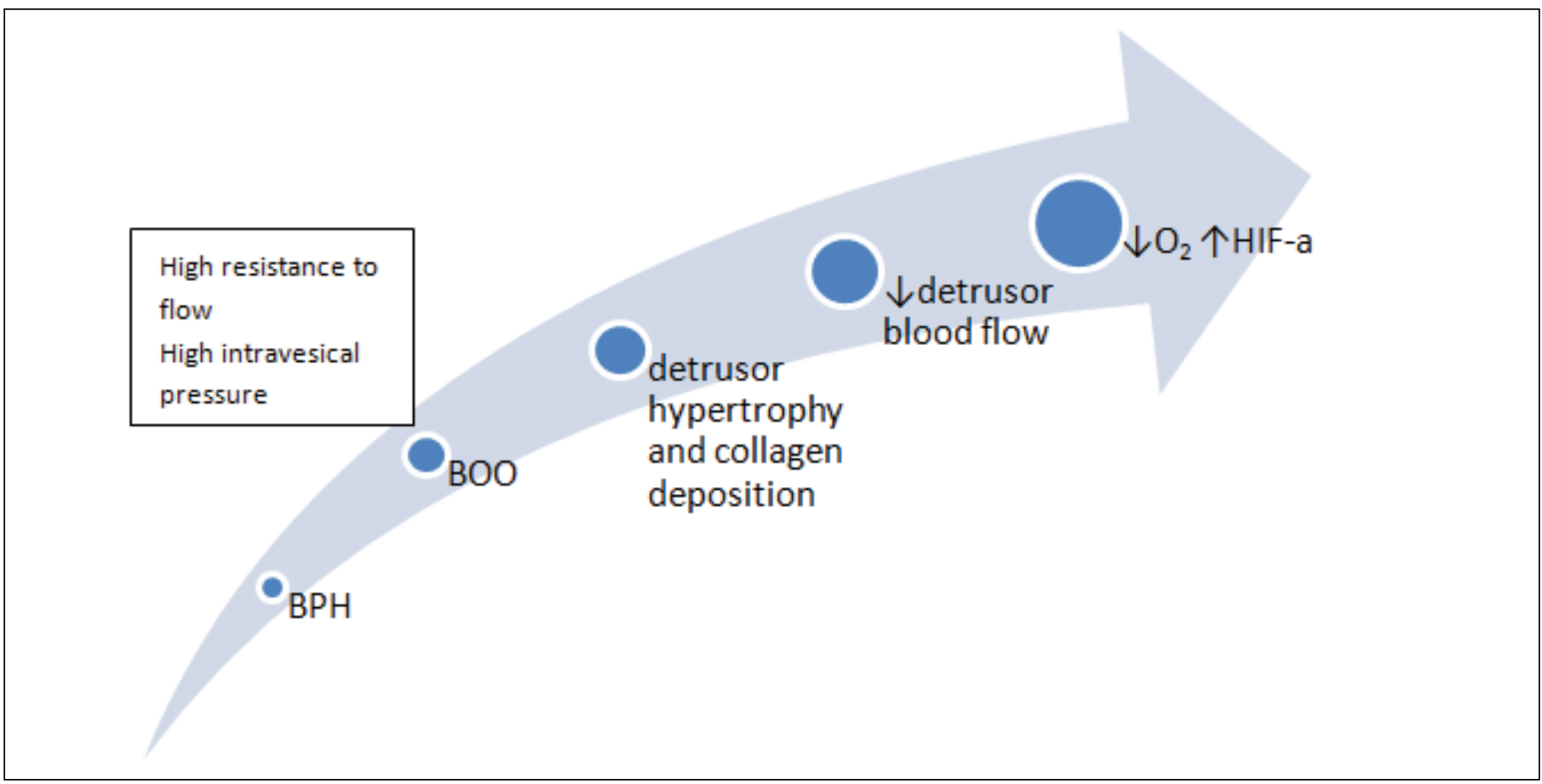

Fig. 2a. Hypoxia and increased expression of hypoxia inducible factor-a (HIF-a) are observed during the progression of BPH. BPH: benign prostate hyperplasia; B00: bladder outlet obstruction; HIF-a: hypoxia-induced factor a; $\uparrow$ : increased; $\downarrow$ : reduced. 
genated hemoglobin over the course of voiding in patients with LUTS compared to asymptomatic subjects. Their results are in agreement with the study by Farag and colleagues. ${ }^{37}$ Moreover, the significantly reduced detrusor blood flow in both full and empty bladder states was also demonstrated by Doppler ultrasonography in patients with BOO. ${ }^{38}$

Contrary to these findings, previous publications reported either inconsistent variations in blood flow during $\mathrm{BOO}^{39}$ or increased blood flow with increasing volume and pressure; ${ }^{40}$ however, these studies were either experimental (not performed on human bladders) or reporting results from early and/or very mild phases of obstruction.

It has been established that the obstructed bladder commonly exhibits evidence of decreased aerobic metabolism, increased anaerobic metabolism and reduced high-energy phosphate content. ${ }^{41}$ As a result to hypoxia, obstructed bladders appear hypervascular ${ }^{22}$ and partially denervated ${ }^{42}$ and exhibit alterations in the mitochondrial structure and function ${ }^{43-45}$ and the glycogen content. ${ }^{46,47}$ Obstruction also induces protein oxidation in the detrusor smooth muscle ${ }^{48}$ lactic acid, due to the anaerobic metabolism, accumulates causing contractile dysfunction. ${ }^{49}$ These findings suggest that ischemia and hypoxia are responsible for the development of bladder dysfunction in BOO. ${ }^{24,25}$ However, it is not known whether this is mediated directly through an effect on the detrusor smooth muscle $\mathrm{e}^{50}$ or as a result of neuronal loss and subsequent smooth muscle changes. ${ }^{51}$ Animal studies in decompensated bladders showed that the severity of contractile dysfunction was correlated with the magnitude of the decrease in blood flow to the muscle compartment, supporting the hypothesis that ischemia is an etiological factor for bladder decompensation after $\mathrm{BOO} .{ }^{29}$

\section{Mitochondria-ATP-glucose metabolism}

Mitochondrial enzyme activity is crucial in the energy production and contractility of detrusor muscle ${ }^{52}$ and it has been shown to increase with the severity of partial BOO in the male. ${ }^{45}$ As the obstruction progresses, increased oxidative stress in the detrusor muscle occurs, leading to a significantly higher incidence and proportion of mitochondrial DNA deletions. ${ }^{44}$ Electron microscopy evaluation of the obstructed rabbit bladder showed that mitochondria within detrusor muscle cells become progressively more swollen. Six weeks post-obstruction, similarly swollen mitochondria are also present in other cell types within the bladder wall, such as fibroblasts, Schwann cells, endothelium and perivascular smooth muscle. These findings of mitochondrial damage have been interpreted as evidence of ischemic damage of the bladder wall as a consequence of outflow obstruction..$^{53}$ Similar mitochondrial damage has been noted in human detrusor smooth muscle cells in biopsy samples removed from patients with bladder outflow obstruction. ${ }^{14}$
Currently, many investigators consider mitochondrial alteration a crucial factor in voiding dysfunction and hypothesize that severe and irreversible mitochondrial damage, marked by disruption of outer membrane, could explain the frequent persistence of symptoms after removing the BOO in men..$^{54}$

Furthermore, during obstruction, mitochondrial enzyme activity subsides, leading to impaired oxidative metabolism, as evidenced by specific decreases in the activity of citrate synthase (CS), malate dehydrogenase and cytochrome oxidase.$^{55}$ ATP provides most of the cellular energy required to maintain cell function. ${ }^{56}$ Adequate cytosolic ATP concentration is maintained by anaerobic metabolism of glucose to pyruvate and subsequent oxidative metabolism of pyruvate to $\mathrm{CO}_{2}$ and $\mathrm{H}_{2} \mathrm{O}$ within the mitochondria through the tricarboxylic acid (TCA) cycle and respiratory chain pathway. ${ }^{57} \mathrm{CS}$ is the rate-limiting enzyme of the TCA cycle, which provides substrates for the respiratory chain. A reduction in respiratory chain substrates would lead to decreased oxidative phosphorylation (i.e., decreased ATP synthesis). Bladder biopsies from men with significant obstructive symptoms, secondary to $\mathrm{BPH}$, have demonstrated a marked decrease in CS activity compared to bladder samples isolated from unobstructed men of the same age. ${ }^{58}$

There is also evidence of reduced aerobic and increased anaerobic metabolism in obstructed bladders. Partial obstruction of the rabbit bladder induces a shift from aerobic to anaerobic metabolism, as evidenced by the shift in glucose metabolism from $\mathrm{CO} 2$ to lactic acid generation. Similarly, there is a marked decrease in the metabolism of pyruvate to $\mathrm{CO} 2 .^{59}$

\section{Glycogen content}

It has been demonstrated that during obstruction the bladder muscle reduces its own oxygen supply by producing pressures that compress the small blood vessels. ${ }^{33,34}$ This prompts parts of the muscle to function anaerobically and glycogen may be used as an alternative energy supplier ${ }^{47}$ In chronic ischemic periods, the bladder may adapt by increasing the amount of glycogen stored in muscles cells. In an animal model, de Jong and colleagues showed that glycogen deposition in the bladder wall is directly related to bladder function during obstruction; ${ }^{46}$ the strongest glycogen deposition was found in bladders with the highest pressures, lowest compliance and highest contractility. At first, little deposition occurred close to the serosal side of the detrusor layer and, later on, the strongest accumulation appeared throughout the whole detrusor layer up to the urothelium. The authors concluded that glycogen content is a clear marker of the severity of the functional changes of the urinary bladder during obstruction and they claimed that analyzing glycogen deposits may give insight in the severity of bladder 
damage and contribute to an accurate prognosis of bladder function. ${ }^{46}$ de Jong and colleagues also state that glycogen concentration could be used to recognize a bladder in the decompensation phase. From a clinical point of view, the development of fibre-optic based Raman spectroscopy for in vivo tissue analysis could be used to identify glycogen content and replace the invasive urodynamic pressure-flow study to diagnose $\mathrm{BOO}$ in men. ${ }^{60}$

\section{Denervation}

The urinary bladder stores urine for most of the day, a process facilitated by $\beta$-adrenergic receptor-mediated detrusor relaxation (predominately $\beta_{3}$-subtype) and $\alpha 1$-adrenergic receptor-mediated contraction of the bladder neck. ${ }^{61}$ In the bladder, $\beta$-adrenergic receptors predominate over $\alpha$-adrenergic receptors and the response of the normal detrusor to the neurotransmitter norepinephrine is relaxation. ${ }^{61}$ Physiological voiding is caused by detrusor contraction, induced by muscarinic receptor (preferentially M3) stimulation by the endogenous neurotransmitter acetylcholine. ${ }^{62}$

The occurrence of storage (irritative) symptoms upon BOO, clearly shows that the obstruction impairs voiding and storage function. However, the relief of $\mathrm{BOO}$ does not always resolve storage symptoms and this may be due to the persistence of the BOO-induced alterations in the bladder wall, even after the removal of obstruction. Such alterations may occur in the innervation level.

Several human bladder studies showed a significant loss of innervation (denervation) associated with obstructive dysfunction secondary to $\mathrm{BPH} .{ }^{42}$ Neurones are known to be very sensitive to hypoxic damage, with grey matter more easily damaged than white. ${ }^{63}$ Denervation may arise because of damage to postganglionic parasympathetic neurones within the bladder wall and this damage may be caused by the transient bladder ischemia that occurs during obstructed micturition. ${ }^{64}$ Moreover, the partial bladder denervation during BOO may appear more on the cholinergic than on the sympathetic side of the system, as this form is more dominant in the bladder. ${ }^{65} \mathrm{~A} 56 \%$ reduction in the number of acetylcholine-positive nerves was demonstrated in bladder biopsies obtained from obstructed compared to nonobstructed men. ${ }^{66}$ Counts of nerve profiles confirmed the reduced density of autonomic innervation and not merely a decrease in the concentration of AchE.

The consistently reported relative denervation of the enlarged bladder can at least partly explain the reduced contractile responses to field stimulation under conditions of severe and/or long lasting BOO, due to a reduced availability of contractile transmitter. ${ }^{65}$ Postsynaptic nerve loss causes the neurogenic contractile dysfunction that results in decreased emptying, increased residual volume and chronic distension characteristic of early decompensation.
In any case, none of these findings can explain the bladder overactivity typically associated with BOO, as all would favour underactivity of the detrusor. The storage symptoms observed in patients with $\mathrm{BOO}$ could theoretically be explained by a decreased $\beta$-adrenergic input. In this context, new treatment strategies currently target $\beta_{3}$-adrenoceptors to reduce storage symptoms. ${ }^{67}$ Although there are concerns regarding the impact of these drugs in the detrusor contraction of patients with $\mathrm{BOO}$, in a recent study, the $\beta_{3}$-adrenoceptor agonist mirabegron was evaluated and found to be safe. ${ }^{68}$

\section{Conclusion}

Bladder dysfunction secondary to $\mathrm{BPH}$ is a major affliction of the aging male. Bladder modifies its structure in order to compensate the increased resistance to flow. As a result there is a significant decrease in detrusor blood flow, especially in the late period of the obstruction. During the obstruction and hypoxia period, there are 6 major alterations of bladder wall morphology and detrusor biochemistry (Fig. 2b):

1) Muscle enlargement and collagen deposition;

2) Mitochondrial DNA deletions, mitochondrial damage and reduced mitochondrial substrate (e.g., glucose) utilization;

3) Decreased mitochondrial enzyme activity leading to decreased oxidative metabolism and ATP synthesis;

4) Reduced aerobic and increased anaerobic metabolism leading to lactic acid accumulation;

5) Glycogen deposition, as an alternative energy supplier; and

6) Reduced cholinergic nerve density and denervation. In the case of long-lasting BOO, mitochondrial damage may become irreversible and this could explain the persistence of symptoms after relief of $\mathrm{BOO}$ in men.

Competing interests: Dr. Komninos and Dr. Mitsogiannis all declare no competing financial or personal interests.

This paper has been peer-reviewed.

\section{References}

1. Boyle P, Robertson C, Mazzetta C, et al. The prevalence of lower urinary tract symptoms in men and women in four centres. The UrEpik study. BJU Int 2003;92:409-14. http://dx.doi.org/10.1046/j.1464410X.2003.04369.X

2. Abrams $\mathrm{P}$, Cardozo L, Fall M, et al. The standardization of terminology of lower urinary tract function: Report from the standardization sub-committee of the international continence society. Neurourol Urodynamics 2002;21:167-78. http://dx.doi.org/10.1002/nau.10052

3. Andersson KE. Storage and voiding symptoms: Pathophysiologic aspects. Urology 2003;62:3-10. http:// dx.doi.org/10.1016/i.urology.2003.09.030

4. Lepor H. Nonoperative management of benign prostatic hyperplasia. J Urol 1989;141:1283-9. 


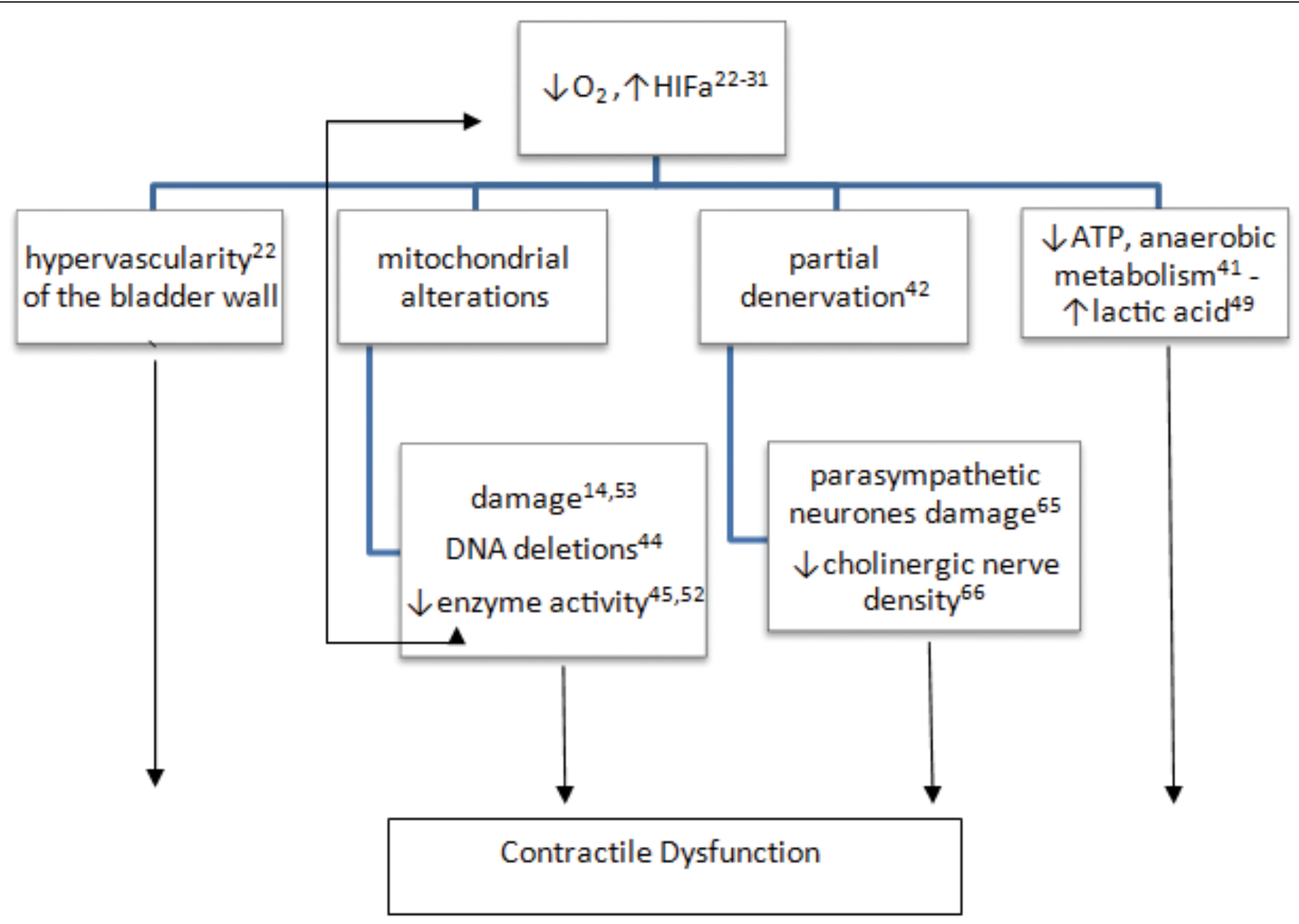

Fig. 2b. Obstruction-induced alterations occur within the urinary bladder resulting in contractile dysfunction. ATP: adenosine triphosphate; HIF-a: hypoxia induced factor $a, \uparrow$ :increased, $\downarrow$ :reduced.

5. Backhaus $B O$, Kaefer $M$, Haberstroh KM, et al. Alterations in the molecular determinants of bladder compliance at hydrostatic pressures less than $40 \mathrm{~cm}$. H20. J Urol 2002;168:2600-4. hittp://dx.doi. org/10.1016/50022-5347(05)64226-7

6. Yamaguchi 0 . Response of bladder smooth muscle cells to obstruction: Signal transduction and the role of mechanosensors. Urology 2004;63:11-6. http://dx.doi.org/10.1016/i.urology.2003.12.002

7. Burkhard FC, Lemack GE, Zimmen PE, et al. Contractile protein expression in bladder smooth muscle is a marker of phenotypic modulation after outlet obstruction in the rabbit model. J Urol 2001;165:963-7. http://dx.doi.org/10.1016/S0022-5347(05)66585-8

8. Malmqvist U, Arner A, Uvelius B. Contractile and cytoskeletal proteins in smooth muscle during hypertrophy and its reversal. Am J Physiol 1991;260:C1085-93.

9. Sjuve R, Haase $H$, Ekblad E, et al. Increased expression of non-muscle myosin heavy chain-B in connective tissue cells of hypertrophic rat urinary bladder. Cell Tissue Res 2001;304:271-8. http://dx.doi. org/10.1007/s004410000262

10. Mannikarottu AS, Disanto ME, Zderic SA, et al. Altered expression of thin filament-associated proteins in hypertrophied urinary bladder smooth muscle. Neurourol Urodyn 2006;25:78-88. http://dx.doi. org/10.1002/nau.20121

11. Lee SD, Akbal C, Jung C. Intravesical pressure induces hyperplasia and hypertrophy of human bladder smooth muscle cells mediated by muscarinic receptors. J Paediatric Urol 2006;2:271-6. http://dx.doi. org/10.1016/i.jpurol.2005.11.015

12. Deveaud $\mathrm{CM}$, Macarak EJ, Kucich U, et al. Molecular analysis of collagens in bladder fibrosis. J Urol 1998;160:1518-27. http://dx.doi.org/10.1016/S0022-5347(01)62606-5

13. Levin RM, Wein AJ, Butyan R, et al. Update on bladder smooth-muscle physiology. World J Urol 1994;12:226-32. http://dx.doi.org/10.1007/BF00191201
14. Levin RM, Haugaard N, $O^{\prime}$ Connor $L$, et al. Obstructive response of human bladder to BPH vs. rabbit bladder response to partial outlet obstruction: A direct comparison. Neurourol Urodyn 2000; 19:609-29. http:// dx.doi.org/10.1002/1520-6777(2000) 19:5<609::AlD-NAU7>3.0.CO;2-H

15. Metcalfe PD, Wang J, Jiao $\mathrm{H}$, et al. Bladder outlet obstruction: Progression from inflammation to fibrosis. BJU Int 2010;106:1686-94. http://dx.doi.org/10.1111/j.1464-410X.2010.09445.x

16. Bing W, Chang S, Hypolite JA, et al. Obstruction-induced changes in urinary bladder smooth muscle contractility: A role for Rho kinase. Am J Physiol Renal Physiol 2003;285: F990-7.

17. Peters SL, Schmidt M, Michel MC. Rho-kinase: A target for treating urinary bladder dysfunction? Trends Pharmacol Science 2006;27:492-7. http://dx.doi.org/10.1016/i.tips.2006.07.002

18. Polyák E, Boopathi E, Mohanan S, et al. Alterations in caveolin expression and ultrastructure after bladder smooth muscle hypertrophy. J Urol 2009;182:2497-503. http://dx.doi.org/10.1016/i. juro.2009.07.011

19. Boopathi E, Gomes CM, Goldfarb R, et al. Transcriptional repression of Caveolin-1 (CAV1) gene expression by GATA-6 in bladder smooth muscle hypertrophy in mice and human beings. Am J Pathol 201 1;178:223651. http://dx.doi.org/10.1016/i.appath.2011.01.038

20. Christ GJ, Andersson KE. Rho-kinase and effects of Rho-kinase inhibition on the lower urinary tract. Neurourol Urodyn 2007;26:948-54. http://dx.doi.org/10.1002/nau.20475

21. Anderson KE, de Groat WC, MCVary KT, et al. Tadalafil for the treatment of lower urinary tract symptoms secondary to benign prostatic hyperplasia: Pathophysiology and mechanisms of action. Neurourol Urodyn 2011;30:292-301. http://dx.doi.org/10.1002/nau.20999

22. Chichester $\mathrm{P}$, Lieb J, Levin SS, et al. Vascular response of the rabbit bladder to short term partial outlet obstruction. Mol Cell Biochem 2000;208:19-26. 
23. Greenland JE, Brading AF. The effect of bladder out flow obstruction on detrusor blood flow changes during the voiding cycle in conscious pigs. J Urol 2001;165:245-8. http://dx.doi.org/10.1097/00005392200101000-00072

24. Elbadawi A, Meyer S, Regnier CH. Role of ischemia in structural changes in the rabbit detrusor following partial bladder outlet obstruction: A working hypothesis and a biomechanical/structural model proposal. Neurourol Urodyn 1989;8:151-62. http://dx.doi.org/10.1002/nau.1930080207

25. Macnab A, Stothers L, Shadgan B. Monitoring detrusor oxygenation and hemodynamics noninvasively during dysfunctional voiding. Adv Urol 2012. http://dx.doi.org/10.1155/2012/676303

26. Rosen R, Altwein J, Boyle P, et al. Lower urinary tract symptoms and male sexual dysfunction: The multinational survey of the aging male (MSAM-7). Eur Urol 2003;44:637-49. http://dx.doi.org/10.1016/i eururo.2003.08.015

27. Rosen RC, Giuliano F, Carson CC. Sexual dysfunction and lower urinary tract symptoms (LUTS) associated with benign prostatic hyperplasia (BPH). Eur Urol 2005;47:824-37. http://dx.doi.org/10.1016/i. eururo.2004.12.013

28. Sasaki T, Larsson H, Tisi D, et al. Endostatins derived from collagens XV and XVIII differ in structural and binding properties, tissue distribution and anti-angiogenic activity. J Mol Biol 2000;301:1179-90. http://dx.doi.org/10.1006/jmbi.2000.3996

29. Schroder A, Chichester P, Kogan BA, et al. Effect of chronic bladder outlet obstruction on the blood flow of the rabbit urinary bladder. J Urol 2001;165:640-6. http://dx.doi.org/10.1097/00005392200102000-00087

30. Levin RM, $\mathrm{O}^{\prime}$ Connor $\mathrm{L}$, Leggett RE, et al. Focal hypoxia of the obstructed bladder wall correlates intermediate decompensation. Neurourol Urodyn 2003;22:156-63. http://dx.doi.org/10.1002/nau.10076

31. Koritsiadis G, Stravodimos K, Koutalellis $G$, et al. Immunohistochemical estimation of hypoxia in human obstructed bladder and correlation with clinical variables. BJU Int 2008;102:328-32. http://dx.doi. org/10.1111/i.1464-410X.2008.07593.x

32. Ghafar MA, Anastasiadis AG, Olsson LE, et al. Hypoxia and an angiogenic response in the partially obstructed rat bladder. Lab Invest 2002;82:903-9. http://dx.doi.org/10.1097/01.LAB.0000021 135.87203.92

33. Greenland JE, Hvistendahl JJ, Andersen $\mathrm{H}$, et al. The effect of bladder outlet obstruction on tissue oxygen tension and blood flow in the pig bladder. BJU Int 2000;85:1109-14. http://dx.doi.org/10.1046/ j.1464-410x.2000.00611.x

34. Azadzoi KM, Pontari M, Vlachiotis J, et al. Canine bladder blood flow and oxygenation: Changes induced by filling, contraction and outlet obstruction. J Urol 1996;155:1459-65. http://dx.doi.org/10.1016/ S0022-5347(01)66307-9

35. Nomiya $M$, Burmeister DM, Sawada $N$, et al. Prophylactic effect of tadalafil on bladder function in a rat model of chronic bladder ischemia. J Urol 2013;189:754-61. http://dx.doi.org/10.1016/i. juro.2012.07.141

36. Macnab AJ, Shadgan B, Stothers $L$, et al. Ambulant monitoring of bladder oxygenation and hemodynamics using wireless near-infrared spectroscopy. Can Urol Assoc J 2013;7:E98-104. http://dx.doi. org/10.5489/cuai.271

37. Farag FF, Meletiadis J, Saleem MD, et al. Near-infrared spectroscopy of the urinary bladder during voiding in men with low urinary tract symptoms: A preliminary study. Biomed Res Int 2013;2013:452857. http://dx.doi.org/10.1155/2013/452857

38. Belenky $A$, Abarbanel $Y$, Cohen $M$, et al. Detrusor resistive index evaluated by Doppler ultrasonography as a potential indicator of bladder outlet obstruction. Urology 2003;62:647-50. http://dx.doi.org/10.1016/ S0090-4295(03)00510-7

39. Kroyer K, Bulow J, Nielsen SL, et al. Urinary blood flow. I. Comparison of clearance of locally iniected 99mtechnetium pertechnate and radioactive microsphere technique in dogs. Urol Res 1990;18:223-6.

40. Kershen RT, Azadzoi KM, Siroky MB. Blood flow, pressure and compliance in the male human bladder. $J$ Urol 2002;168:121-5. http://dx.doi.org/10.1016/S0022-5347(05)64843-4

41. Lin AT, Chen MT, Yang CH, et al. Blood flow of the urinary bladder: Effects of outlet obstruction and correlation with bioenergetic metabolism. Neurourol Urodyn 1995;14:285-92. http:// dx.doi.org/10.1002/nau.1930140309

42. Chapple CR, Milner P, Moss HE, et al. Loss of sensory neuropeptides in the obstructed human bladder. Br J Urol 1992;70:373-81. http://dx.doi.org/10.1111/i.1464-410X.1992. tb15791.x

43. Damaser MS, Haugaard N, Uvelius B. Partial obstruction of the rat urinary bladder: Effects on mitochondrio and mitochondrial glucose metabolism in detrusor smooth muscle cells. Neurourol Urodyn 1997;16:601-7. http://dx.doi.org/10.1002/(SICI) 1520-6777(1997)16:6<601::AID-NAU9>3.0.C0;2-1

44. Lu SH, Chang LS, Yang AH, et al. Mitochondrial DNA deletion of the human detrusor after partial bladder outlet obstruction-correlation with urodynamic analysis. Urology 2000;55:603-7. http://dx.doi. org/10.1016/50090-4295(99)00609-3

45. LuSH, Wei YH, Chang LS, et al. Morphological and morphometric analysis of human detrusor mitochondria with urodynamic correlation after partial outlet obstruction. J Urol 2000;163:225-9. http://dx.doi. org/10.1016/50022-5347(05)68011-1
46. de Jong BWD, Wolffenbuttel KP, Scheepe JR, et al. The detrusor glycogen content of a de-obstructed bladder reflects the functional history of that bladder during PB00. Neurourol Urodyn 2008;27:454-60. http://dx.doi.org/10.1002/nau.20567

47. Pessina F, Solito R, Maestrini D, et al. Effect of anoxia-glucopenia and resuperfusion on intrinsic nerves of mammalian detrusor smooth muscle: Importance of glucose metabolism. Neurourol Urodyn 2005;24:38996. http://dx.doi.org/10.1002/nau.20094

48. Siflinger-Birnboim A, Levin RM, Hass MA. Partial outlet obstruction of the rabbit urinary bladder induces selective protein oxidation. Neurourol Urodyn 2008;27: 532-9. http://dx.doi.org/10.1002/nau.20557

49. Lin ATL, Shiao MS, Chen CJ, et al. Energetics of detrusor contraction: Effects of outlet obstruction. Neurourol Urodyn 1992;11:605-14. http://dx.doi.org/10.1002/nau.1930110604

50. Zhao Y, Levin SS, Wein AJ, et al. Correlation of ischemia/reperfusion or partial outlet obstruction-induced spectrin proteolysis by calpain with contractile dysfunction in rabbit bladder. Urology 1997;49:293-300. http://dx.doi.org/10.1016/50090-4295(96)00452-9

51. Yokoyama 0 , Kawaguchi K, Hisazumi H. Denervation super sensitivity of the detrusor muscle due to bladder over distension, with special reference to the relationship between super sensitivity, and changes in the connective tissue. Hinyokika Kiyo 1985;31:2127-34.

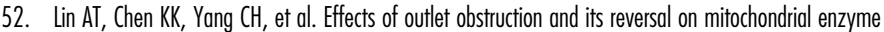
activity in rabbit urinary bladders. J Urol 1998;160:2258-62. http://dx.doi.org/10.1016/S00225347(01)62306-1

53. Gosling JA, Kung $L S$, Dixon JS, et al. Correlation between the structure and function of the rabbit urinary bladder following partial outlet obstruction. J Urol 2000;163:1349-56. http://dx.doi.org/10.1016/ S0022-5347(05)67776-2

54. Mirone V, Imbimbo C, Longo N, et al. The detrusor muscle: An innocent victim of bladder outlet obstruction. Eur Urol 2007;51:57-66. http://dx.doi.org/10.1016/i.eururo.2006.07.050

55. Hsu TH-S, Levin RM, Wein AJ, et al. Alterations of mitochondrial oxidative metabolism in rabbit urinary bladder after partial outlet obstruction. Mol Cell Biochem 1994;141:47-55. http://dx.doi.org/10.1007/ BF00935590

56. Campbell JD, Agubosim S, Paul RJ. Compartmentation of metabolism and function in vascular smooth muscle: Quantitation of Na-pump activity and aerobic glycolysis. FASEB J 1988;2:A755.

57. Siegman MJ, Butler TM, Mooers SU, et al. Chemical energetics of force development, force maintenance, and relaxation in mammalian smooth muscle. J Gen Physiol 1980;76:609-29. http://dx.doi. org/10.1085/igp.76.5.609

58. Levin RM, Haugaard N, Mogavero L, et al. Biochemical evaluation of obstructive bladder dysfunction in men secondary to BPH: A preliminary report. Urology 1999;53:446-50. http://dx.doi.org/10.1016/ S0090-4295(98)00497-X

59. Kato K, Lin AT-L, Wein AJ, et al. Effect of outlet obstruction on glucose metabolism of the rabbit urinary bladder. J Urol 1990; 143:844-7.

60. Hanchanale VS, Rao AR, Das S. Raman spectroscopy and its urological applications. Indian I Urol 2008:24:444-50. http://dx.doi.org/10.4103/0970-1591.39550

61. Michel MC, Vrydag W. $\alpha$ 1-; $\alpha 2$ - and $\beta$-adrenoceptors in the urinary bladder, urethra and prostate. $\mathrm{Br} J$ Pharmacol 2006;147:S88-119. http://dx.doi.org/10.1038/si.bip.0706619

62. Andersson KE. Detrusor myocyte activity and afferent signaling. Neurourol Urodyn 2010;29:97-106. http://dx.doi.org/10.1002/nau.20784

63. Haddad GG, Jiang C. 02 deprivation in the central nervous system: On mechanisms of neuronal response, differential sensitivity and iniury. Prog Neurobiol 1993:40:277-318. http://dx.doi.org/10.1016/03010082(93)90014-

64. Geloso DA, Levin RM. Effect of partial outlet obstruction on the myogenic response to field stimulation. Gen Pharmacol 1998;31:291-5. http://dx.doi.org/10.1016/S0306-3623(97)00437-0

65. Michel MC, Barendrecht MM. Physiological and pathological regulation of the autonomic control of urinary bladder contractility. Pharmacology \& Therapeutics 2008;117:297-312. http://dx.doi.org/10.1016/i. pharmthera.2007.12.001

66. Cumming JA, Chisholm GD. Changes in detrusor innervation with relief of oufflow tract obstruction. $B r J$ Urol 1992;69:7-11. http://dx.doi.org/10.1111/j.1464-410X.1992.tb15448.x

67. Otsuki H, Kosaka T, Nakamura $\mathrm{K}$, et al. $\beta 3$-adrenoceptor agonist mirabegron is effective for overactive bladder that is unresponsive to antimuscarinic treatment or is related to benign prostatic hyperplasia in men. Int Urol Nephrol 2013;45:53-60. http://dx.doi.org/10.1007/s11255-012-0343-5

68. Nitti V, Rosenberg $S$, Mitcheson HD, et al. Urodynamics and safety of the $\beta 3$-adrenoceptor agonist Mirabegron in males with lower urinary tract symptoms and bladder outlet obstruction. J Urol 2013;190:1320-7. http://dx.doi.org/10.1016/i.juro.2013.05.062

Correspondence: Dr. Iraklis C. Mitsogiannis, $2^{\text {nd }}$ Department of Urology, University of Athens, Sismanoglio Hospital, 1 Sismanogliou Street, 15126 Maroussi, Athens, Greece; imitsog@med.uoa.gr 